\title{
O USO DE DISTALIZADORES PARA A CORREÇÃO DA MÁ OCLUSÃO DE CLASSE II-
}

\section{THE USE OF DISTALIZATION FOR THE CORRECTION OF CLASS II $M A L O C C L U S I O N$}

\author{
Milene Azevedo Portela Lopes** \\ Dênis Clay Lopes Santos*** \\ Daniel Negrete**** \\ Everton Flaiban*****
}

\begin{abstract}
RESUMO
O objetivo deste trabalho é realizar uma revisão da literatura e apresentar alguns dos aparelhos e dispositivos, utilizados para a correção da Classe II de Angle, abordar suas vantagens e desvantagens, método de ação e efeitos secundários indesejáveis e mostrar a efetividade dos mesmos para a correção da má oclusão de Classe II. A má oclusão de Classe II caracteriza-se por um relacionamento incorreto dos arcos superior e inferior, por alterações esqueléticas, dentárias ou por uma combinação destes fatores. Essa má oclusão apresenta uma prevalência em torno de $42 \%$ em relação às demais, o que explica o grande interesse por pesquisadores em estudá-las e elaborar formas mais adequadas de tratamento. O tratamento da má oclusão de Classe II pode ser realizado por uma infinidade de abordagens terapêuticas e uma delas consiste em converter a relação molar de Classe II em Classe I, através da movimentação distal de molares superiores. O aparelho extrabucal (AEB) pode ser utilizado no tratamento ortopédico e ortodôntico, sendo eficiente na distalização uni ou bilateral de molares superiores. Dentre os distalizadores intrabucais estão os aparelhos Pêndulo e Pendex, os quais agem na face palatina dos molares, distalizando-os. Os elásticos intermaxilares de Classe II possuem a característica de apresentar força constante, fazendo com que a movimentação ortodôntica permaneça a mesma, sem degradação da força. Os mini-implantes foram desenvolvidos para tratamento ortodôntico, por promoverem uma ancoragem máxima, se mostram resistentes à força ortodôntica aplicada, podendo ser utilizados para distalizar os molares superiores.
\end{abstract}

DESCRITORES: Má Olcusão de Angle Classe II

\section{ABSTRACT}

The objective of this study is to conduct a literature review and present some of the equipment and devices used for the correction of Class II malocclusion, addressing their advantages and disadvantages, method of action and undesirable side effects, and show the effectiveness of the same for the correction of Class II malocclusion. The Class II malocclusion characterized by an incorrect relationship of the upper and lower arches, by skeletal and dental abnormalities, or by a combination of these factors. This malocclusion has a prevalence of about $42 \%$ in relation to others, which explains the great interest for researchers on studying them and developping better ways of treatment. The treatment of Class II malocclusion can be accomplished by a multitude of therapeutic approaches, one of them is to convert the mole ratio of Class II to Class I by distal movement of molars. The extra oral appliance (AEB) can be used in orthopedic and orthodontic treatment, being effective in unilateral or bilateral distalization of molars. Among the intraoral distalization appliances are Pendulum and Pendex, which act on the lingual face of the molars, distalizing them. The use of elastics Class II, which have the characteristic to provide constant force, making orthodontic movement remains the same without degradation of strength. In recent years, the mini implants were developed for use in orthodontic treatment for promoting a maximum anchorage, they are resistant to the orthodontic force applied and may be used for distalizing the upper molars.

DESCRIPTORS: Malocclusion, Angle Class II

\footnotetext{
* Universidade Cruzeiro do Sul - Especialização em Ortodontia

** Especialista em Ortodontia e Ortopedia facial - UNICSUL, Especialista em Dentística - ABO

*** Professor responsável pela disciplina de Ortodontia e Ortopedia Facial da Universidade Cruzeiro do Sul. Coordenador da Pós-graduação em odontologia da clínica de pós-graduação do Centro Universitário Módulo. Doutorado e Mestrado em Saúde da Criança e do adolescente - Faculdade de Ciências Médicas - UNICAMP. Especialista em Ortodontia e Ortopedia facial.

***** Mestre em Ortodontia - UNICID. Especialista em Ortodontia e Ortopedia facial - UNICSUL

***** Mestrando em Ortodontia - UNICID. Especialista em Ortodontia e Ortopedia facial - UNICSUL
} 
LOPES MAP

SANTOS DCL

NEGRETE D

FLAIBAN E

O USO DE

DISTALIZADORES

PARA A CORREÇÃO

DA MÁ OCLUSÃO

DE CLASSE II

$224 \ldots$

REV, ODONTOL.

UNIV. CID. SÃO

PAULO

2013; 25(3): 223-32, SET-DEZ

\section{N T RO DUÇ ÃO}

A má oclusão de Classe II caracteriza-se por um relacionamento incorreto dos arcos superior e inferior, tanto por alterações esqueléticas como dentárias ou, ainda, por uma combinação desses fatores.

Angle, em 1899, considerando o posicionamento dentário de acordo com a relação oclusal entre o primeiro molar superior e o inferior, classificou a má oclusão de Classe II como um relacionamento distal do arco dentário inferior em relação ao superior. Com o advento da radiografia cefalométrica, Simon, em 1926, observou que, além do determinante dentário, havia fatores esqueléticos envolvidos no desenvolvimento da má oclusão de Classe II. Segundo Jarabak (1972), a má oclusão Classe II pode ser classificada em dentária, dentoalveolar, funcional ou neuromuscular, esquelética ou uma combinação de dentoalveolar e esquelética.

A má oclusão de Classe II apresenta uma prevalência em torno de $42 \%$ em relação às demais más oclusões, sendo que 26,61\% são relacionados à Classe II dentária e 15,39\% à esquelética, o que explica o interesse dos pesquisadores em estudá-las e também as tentativas de elaborar formas mais adequadas de tratamento ${ }^{1}$. Diante disso, esse tipo de má oclusão com características dentoesqueléticas tem sido alvo de constantes estudos na busca de meios alternativos extra ou intrabucais, no intuito de corrigir a relação de Classe II.

O tratamento da má oclusão de Classe II pode ser realizado por uma infinidade de abordagens terapêuticas. Uma delas consiste em converter a relação molar de Classe II em Classe I, por meio da movimentação distal dos molares superiores numa etapa inicial, seguida da retração dos pré-molares e, posteriormente, do segmento anterior.

Dentre os muitos métodos propostos para o tratamento da Classe II, encontra-se o aparelho extrabucal (AEB), que promove alteração ortopédica e ortodôntica, sendo eficiente na distalização uni ou bilateral de molares superiores permanentes. Em grande diversidade, os aparelhos de ancoragem intrabucal, os chamados distalizadores intrabucais, surgiram para promover uma ação mais ortodôntica; possuem uma resultante das forças aplicadas na face vestibular ou palatina dos molares superiores para a correção da Classe II. Dentre os dispositivos intrabucais que atuam na face palatina do molar superior encontram-se o Pêndulo de Hilgers e a sua variação, o Pendex e, como vestibulares, acessórios como os elásticos de Classe II e os mini-implantes ${ }^{2}$.

O objetivo deste trabalho é realizar um revisão da literatura e apresentar alguns dos aparelhos e dispositivos extra e intrabucais, utilizados para a correção da Classe II de Angle, abordar suas vantagens e desvantagens, método de ação e efeitos secundários indesejáveis e mostrar sua efetividade para a correção da má oclusão de Classe II.

\section{REVISÃO DA LITERATURA}

A revisão da literatura irá apresentar, de maneira objetiva e sucinta, uma amostra da diversidade de estudos realizados sobre os aparelhos para a correção da Classe II, quando há a necessidade de distalização dos molares superiores.

\section{Aparelho Extrabucal}

$\mathrm{O}$ uso de força extrabucal surgiu no começo do século XIX, em 1802, quando Cellier, verificando a necessidade de desenvolver um dispositivo de ancoragem extrabucal para prevenir a luxação de mandíbula durante as extrações dentárias, deu início à utilização desse aparelho. $\mathrm{O}$ aparelho extrabucal (AEB) de tração cervical desenvolvido, em 1947, por Silas Kloehn, muito utilizado e estudado no decorrer de várias décadas, possui algumas vantagens, ressaltando-se o reposicionamento anteroposterior das bases apicais, a obtenção da chave de oclusão normal dos molares, a modificação dos planos oclusal e palatino e redução do trespasse horizontal ${ }^{3}$.

O AEB é um aparelho removível ativo usado como ancoragem ou com a finalidade de distalizar os molares superiores. É considerado o aparelho mais eficiente para esse propósito, conseguindo distalizar coroa e raiz dos molares (Figuras 1 e 2). 


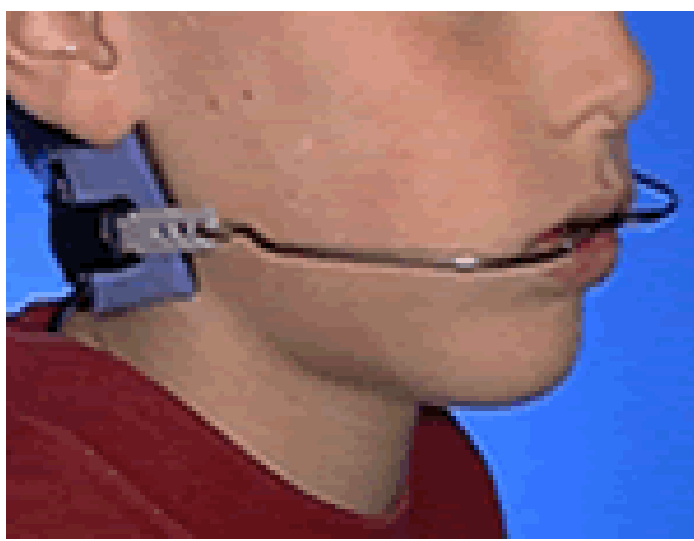

Figura 1 - $A E B$ - foto extrabucal

Na correção da Classe II dentária, provavelmente instalada pela perda precoce do molar decíduo, o AEB promove a distalização do molar por força ortodôntica. Na Classe II esquelética, cerca de $70 \%$ dos casos são decorrentes da falta de crescimento da mandíbula e $30 \%$ por protrusão da maxila. Nesses casos, o AEB tem uso ortopédico, para que o dente seja distalizado 4 .

Segundo Ricketts et al. ${ }^{5}(1983)$, nos braquifaciais, o AEB cervical poderá estabilizar o plano mandibular e o eixo facial, rotacionando a mandíbula no sentido anti-horário, podendo diminuir a altura facial inferior e o ângulo do plano mandibular. O AEB combinado deverá ser utilizado nos pacientes dolicofaciais com Classe II, divisão 1 , para que a mandíbula não gire no sentido horário e não aumente a altura facial inferior. Quando mal empregado, o aparelho extrabucal provoca efeito extrusivo dos molares superiores permanentes, aumento da altura facial inferior e rotação do plano mandibular no sentido horário, agravando ainda mais a má oclusão, principalmente nos pacientes com padrão dolicofacial ${ }^{6}$.

Em 1992, Burke e Jacobson ${ }^{7}$ estudaram as alterações esqueléticas no sentido vertical em pacientes com más oclusões de Classe II, $1^{\text {a }}$ divisão, que apresentavam inicialmente o ângulo do plano mandibular aumentado, tratados com o aparelho extrabucal de tração cervical e occipital. Confirmou-se a extrusão dos molares superiores, quando da utilização da tração cervical, porém não se verificou alteração no sentido vertical da face inferior.

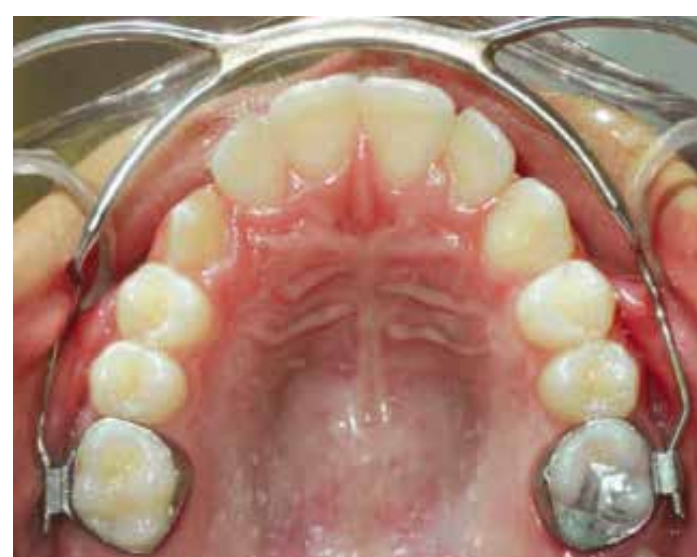

LOPES MAP

SANTOS DCL

NEGRETE D

FLAIBAN E

O USO DE

DISTALIZADORES

PARA A

CORREÇÃO DA

MÁ OCLUSÃO DE

CLASSE II

Figura 2 - $A E B$ - foto intrabucal

Beckwith et al. ${ }^{8}$ (1999) relacionaram a falta de cooperação do paciente no uso do AEB ao prolongamento acentuado do tratamento, ao insucesso e à necessidade do replanejamento dos casos. Henriques et al. ${ }^{9}$, em 1999, reuniram os principais efeitos dentoesqueléticos com o aparelho extrabucal de tração occipital. Resumiram os efeitos ortodônticos em: distalização dos molares superiores, para a obtenção da relação molar normal, controle de uma possível extrusão dos molares superiores ou, em alguns casos, a possibilidade de intruí-los; tendência de inclinação das raízes para a distal e baixo risco de impacção dos segundos molares superiores permanentes. No ano seguinte, os autores apresentaram dois casos clínicos, um utilizando o aparelho extrabucal com tração cervical e outro com tração occipital, e concluíram que o tratamento dessa má oclusão em pacientes com padrão de crescimento facial vertical com os dois tipos de tração mostrou-se eficiente.

Em 2004, Nahás ${ }^{10}$ concluiu que o tratamento com o aparelho extrabucal de tração occipital alterou a tendência de deslocamento anterior da maxila de modo significante, o crescimento mandibular não foi alterado pelo tratamento e houve uma significativa melhora na relação maxilomandibular e a relação de Classe Il foi corrigida. Maria et al. ${ }^{11}$ (2005), ao analisarem a influência da cooperação no planejamento e tempo de tratamento da má oclusão de Classe II, afirmam que, ao optarmos pela correção por meio da distalização bilateral dos segmentos posteriores através do AEB, fica bastante evidente

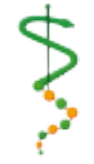

REV. ODONTOL.

UNIV, CID , SÃO PAULO 
LOPES MAP

SANTOS DCL

NEGRETE D

FLAIBAN E

O USO DE

DISTALIZADORES

PARA A CORREÇÃO

DA MÁ OCLUSÃO

DE CLASSE II

\section{6}

REV, ODONTOL.

UNIV, C I D , S ÃO

PAULO

$2013 ; 25(3):$ $223-32$, SET-DEZ uma maior demanda mecânica e principalmente uma exigência muito maior por cooperação por parte do paciente, para que o sucesso do tratamento seja alcançado. Um estudo sobre as alterações decorrentes do uso do aparelho extrabucal na correção da má oclusão de Classe II, $1^{\text {a }}$ divisão, foi realizado por Henriques et al. ${ }^{12}$ em 2007, visando avaliar as alterações de jovens com má oclusão de Classe II, tratados com o aparelho extrabucal de tração occipital. Foram analisadas 100 telerradiografias em norma lateral. O resultado do estudo mostrou que o deslocamento anterior da maxila foi restringido significantemente no grupo experimental. A relação maxilomandibular melhorou, a movimentação de distalização dos molares superiores foi significante e o lábio superior demonstrou maior retrusão no grupo experimental. Verificou-se que esse protocolo de tratamento propiciou alterações clínicas relevantes para a correção da má oclusão de Classe II, $1^{\text {a }}$ divisão.

\section{Aparelho Pêndulo/Pendex}

O aparelho Pêndulo foi desenvolvido em 1992 por Hilgers, com a finalidade de promover a distalização dos primeiros e/ ou segundos molares superiores, em pacientes não colaboradores. Apresenta um botão de acrílico (Nance) no palato para ancoragem e molas constituídas com fio de titânio-molibdênio (TMA), que se encaixam nos tubos linguais dos molares e produzem uma força leve e contínua sobre eles. A denominação do aparelho baseou-se na forma com que essas forças são geradas, como se fosse um pêndulo, partindo da linha média do palato em direção aos molares superiores. (Figura 3).

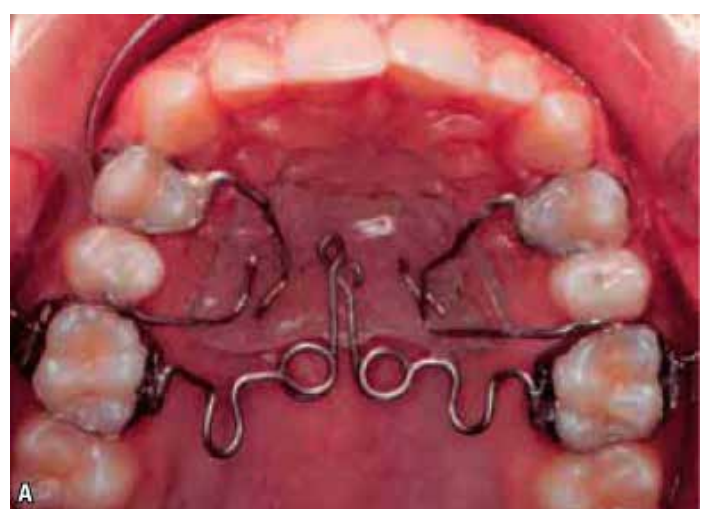

Figura 3 - Aparelho Pêndulo
O aparelho Pendex surgiu da modificação através da colocação de um aparelho expansor na região mediana do palato, quando existe a necessidade de uma expansão transversal da maxila. (Figura 4).

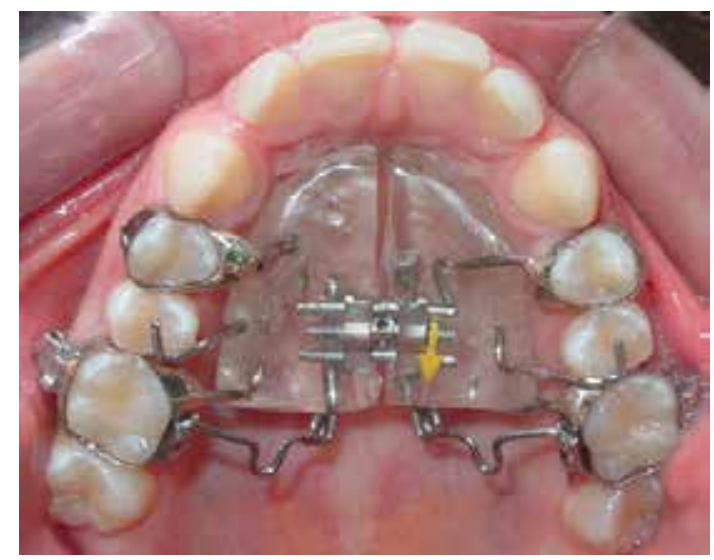

Figura 4 - Aparelho Pendex

Bussick e Mc Namara ${ }^{13}$ (2000) publicaram um artigo com o objetivo de avaliar os efeitos dentoalveolares e esqueléticos do aparelho Pêndulo em pacientes Class II. O estudo foi realizado em 101 pacientes, por meio de telerradiografias obtidas pré e pós-tratamento. A média de distalização do primeiro molar superior foi de $5,7 \mathrm{~mm}$, com uma inclinação distal de $10,6^{0}$. Os dentes na unidade de ancoragem sofreram uma mesialização de $1,8 \mathrm{~mm}$, e os pré-molares apresentaram uma inclinação mesial de $1,5^{0}$. O espaço obtido deveu-se à distalização dos molares em $76 \%$ e em $24 \%$ devido à mesialização dos pré-molares. Os resultados desse estudo sugeriram que o aparelho Pêndulo foi eficaz para distalizar os molares superiores.

Fuziy et al. ${ }^{14}$ (2006) realizaram um estudo no qual avaliaram, em telerradiografias laterais, as alterações dentárias sagitais e verticais decorrentes do emprego do aparelho Pêndulo associado com a ancoragem esquelética, em 13 pacientes, num período de 7 meses. Os resultados evidenciaram que os primeiros molares superiores mostraram uma inclinação para distal e intrusão, as coroas dos primeiros e segundos molares superiores tiveram movimento insignificante de extrusão, e concluíram que o sistema proposto permite alcançar a distalização dos molares superiores com controle da unidade do movimento mesial de pré-molares e caninos, e vestibular de 
incisivos. Santos et al..$^{15}$ (2009) avaliaram os efeitos do aparelho Pendex por meio de uma amostra de 30 modelos de gesso obtidos no início e final da distalização dos molares superiores com o aparelho Pendex em 15 jovens com má oclusão de Classe II, entre 9 e 15 anos. A comparação dos modelos revelou a criação de espaço de $2 \mathrm{~mm}$ na mesial dos primeiros molares após a distalização. Ocorreu uma pequena expansão transversal. Concluíram que é possível aumentar o perímetro do arco superior, com a inclinação dos primeiros molares para distal, pela extrusão da mesial e intrusão da superfície distal dos mesmos, caracterizando um movimento de pêndulo e não de corpo, o que não desqualifica o resultado, mas impõe limites na quantidade de distalização possível durante o planejamento ortodôntico.

\section{Elásticos de Classe II}

O uso de elástico em Ortodontia, iniciado no final do século XIX, tem sido incrementado com a melhora de suas propriedades. Sua utilização é ampla: para substituir as ligaduras metálicas, na movimentação dentária para retração de dentes e fechamento de diastemas, na correção de relações anteroposteriores, correção da linha média, intercuspidação e auxiliares na utilização de aparelhos extrabucais. A aplicação clínica dos elásticos deve ser baseada em evidências científicas de acordo com o tipo de movimentação ou efeito desejado para que os resultados ortodônticos sejam individualizados ${ }^{16}$.

Os elásticos apresentam a característica de manter força constante, fazendo com que a movimentação ortodôntica permaneça a mesma, sem degradação da força. Idealmente, um elástico deve fornecer uma força leve e controlada quanto à direção, movimentando os dentes em conjunto com arcos de aço e alcançando um resultado ótimo, de acordo com o plano de tratamento pré-definido. Caracterizam-se por apoiarem-se na região do canino superior a um molar inferior, podendo ser o primeiro ou o segundo. Podem ser fixados em ganchos presos no fio ou diretamente nos dentes, por meio de ganchos presentes em acessórios como braquetes e tubos ou em fios amarrados no braquete que servirão para fixação dos elásticos. Uma alternativa é a utilização de arcos auxiliares como o sliding-jig, que potencializa o efeito de distalização nos molares superiores. São indicados no tratamento da má oclusão de Classe II, com o intuito de se exercer uma força distal nos dentes superiores e mesial no arco inferior. Entretanto, essas forças geralmente não são paralelas ao plano oclusal, resultando em componentes verticais e horizontais de força, que dependerão da localização e da distância entre os pontos de fixação dos elásticos. Quanto maior for essa distância ântero-posterior, a componente vertical de força poderá ser menor e a componente horizontal será maior. Dessa forma, a extensão do canino superior até o segundo molar inferior pode minimizar os efeitos extrusivos e potencializar a componente horizontal da mecânica aplicada. Com referência à magnitude de força, Cabrera et al. ${ }^{17}$ (2003) indicam a utilização de 200-250g na mecânica com elástico de Classe II.

Philipps $^{18}$ (1993) sugeriu que, além da análise mecânica, é necessária uma análise individual de cada paciente, de acordo com o padrão muscular e o crescimento esquelético. Segundo o autor, o elástico de Classe II tradicional está mais indicado em casos de pacientes com Classe II moderada e dimensão vertical normal, utilizando-se um fio o mais rígido possível no arco superior para controle dos efeitos indesejados. Isso é necessário para anular um componente vertical de força que tende a extruir os incisivos superiores e os molares inferiores, o que resultaria na inclinação do plano oclusal para baixo e para a frente. O mesmo autor contraindica esse tipo de elástico em pacientes Classe II, divisão 1, e face curta (padrão hipodivergente) e em Classe II, divisão 2, com mordida profunda, devido ao efeito indesejado no plano oclusal, no giro da mandíbula e na extrusão dos dentes anteriores superiores. Da mesma forma, contraindica em pacientes Classe II com face longa (padrão hiperdivergente), pois a extrusão dos molares inferiores causaria um giro horário da mandíbula, prejudicando o aspecto facial convexo e aumentando a altura facial anteroinferior.

$\mathrm{Na}$ verdade, o uso de elásticos não
LOPES MAP

SANTOS DCL

NEGRETE D

FLAIBAN E

O USO DE

DISTALIZADORES

PARA A

CORREÇÃO DA

MÁ OCLUSÃO DE

CLASSE II

227

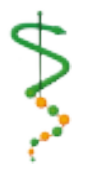

REV. ODONTOL.

UnIV, CID, São

PAULO

2013; 25(3):

$223-32$, SET-DEZ 
LOPES MAP

SANTOS DCL

NEGRETE D

FLAIBAN E

O USO DE

DISTALIZADORES

PARA A CORREÇÃO

DA MÁ OCLUSÃO

DE CLASSE II

228

REV, ODONTOL.

UNIV, CID, SÃO

PAULO

2013; 25(3): $223-32$, SET-DEZ
I SSN 1983-5183

deve ser dispensado apenas devido aos efeitos indesejados que provocam. Deve-se, na verdade, compreender os efeitos favoráveis, de acordo com o planejamento do caso, e associar outros recursos na mecânica utilizada que possam se contrapor às forças indesejadas associadas aos elásticos. Dessa forma, não só os efeitos dentários, mas também os efeitos faciais podem ser equilibrados e resultados mais favoráveis podem ser alcançados.

Um efeito colateral dos elásticos de Classe II, comumente encontrado na clínica ortodôntica, é o giro mesial dos molares inferiores. Vale salientar que esse tipo de efeito colateral não ocorre apenas nos molares, mas em todos os dentes que sirvam de apoio aos elásticos, pois a linha de ação da força sempre vai passar distante do centro de resistência dos dentes. Para minimizar esses efeitos indesejados, podem ser utilizados arcos pesados como os retangulares, arcos com stops justos aos acessórios dos molares, arcos com dobras de pré-ativação, arcos linguais ou palatinos ou outro recurso biomecânico que irá se contrapor a esses efeitos.

$\mathrm{Na}$ terapia Bioprogressiva, utilizam-se os elásticos de Classe II para a distalização do molar superior, associados com arcos segmentados especiais que potencializam a força horizontal de distalização e minimizam as forças verticais extrusivas, utilizando-se a ancoragem cortical promovida pelo Arco Base Inferior ${ }^{19}$.

Não se recomenda utilizar elásticos em arcos contínuos, pois corre-se o risco de deslocar-se o arco inferior para mesial ao mesmo tempo em que ocorrem a extrusão e a retração do arco superior, prejudicando o perfil em caso de mordida profunda, resultando ainda em rotação do plano oclusal no sentido horário e não permitindo a sobrecorreção do setor lateral. O arco seccionado de forças paralelas foi desenvolvido a partir do arco seccionado em "Z" de Ricketts e associado à ancoragem cortical promovida pelo Arco Base Inferior e aos elásticos de Classe II e mostra-se eficaz no tratamento da Classe II, pela distalização dos molares ${ }^{20}$. (Figura 5).

Ao se colocar o elástico no arco seccionado de forças paralelas, ocorre um arqueamento da ponte lateral e, consequen-

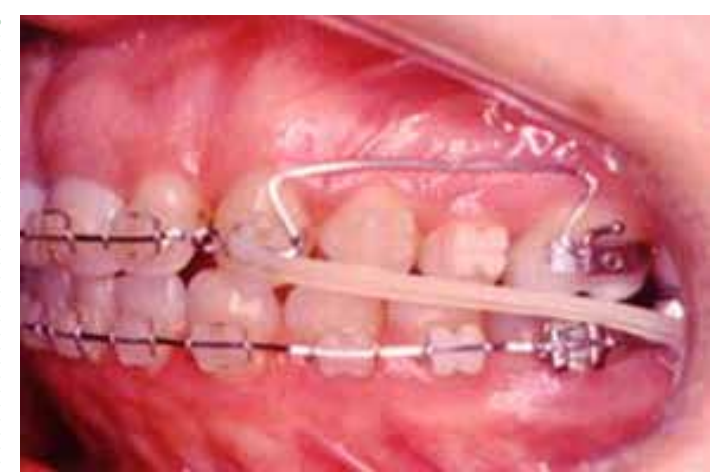

Figura 5 - Elástico de Classe II

temente, um direcionamento da força para o molar. Isso se deve ao fato do gancho estar $2 \mathrm{~mm}$ à frente do braquete do canino, permitindo que o arco deslize no braquete e pressione o molar. Com o gancho de tração elástica mais próximo do plano oclusal diminuímos consideravelmente o vetor extrusivo (vertical), e potencializamos o vetor de distalização (horizontal). Os pré-molares distalizam naturalmente pelo estiramento das fibras periodontais. Uma das vantagens desse tipo de mecânica seccionada é a possibilidade do tratamento uni ou bilateral ${ }^{21}$.

\section{Mini-implantes}

Os mini-implantes (MI) são produzidos com uma liga de titânio grau $\mathrm{V}$, que os torna mais resistentes à fratura. Eles apresentam dimensões entre 1,2 e $2 \mathrm{~mm}$ de diâmetro com 6 a $12 \mathrm{~mm}$ de comprimento. Possuem extremidade em forma de botão para o apoio de módulos elásticos e fios de amarrilho ${ }^{22}$. (Figuas 6 e 7).

Os MI podem ser usados em casos de distalização de molares; são usados para ancoragem ortodôntica e selecionados de acordo com o local de instalação e aplicação clínica desejada. Podem receber carga imediata, porém recomenda-se usar forças de baixa intensidade durante as pri-

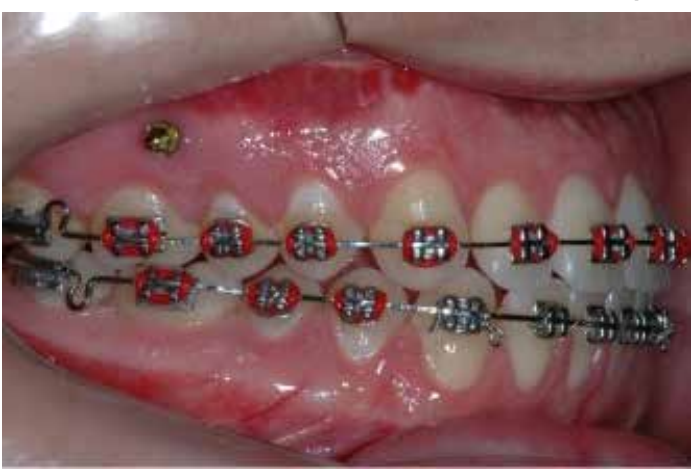

Figura 6 - Mini-implante 


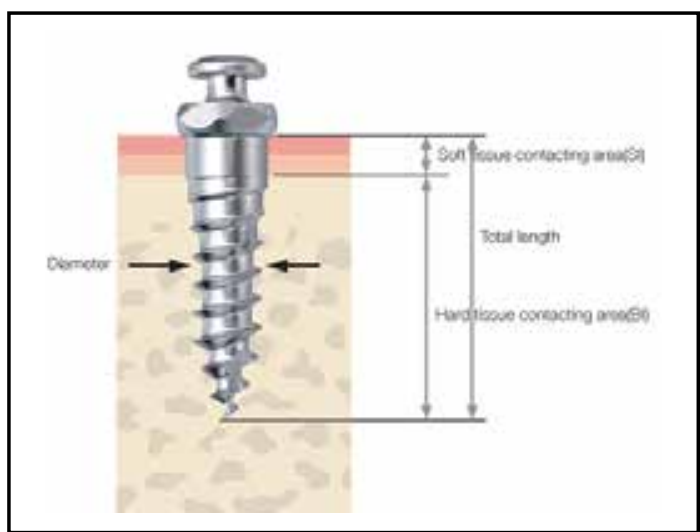

Figura 7 -Mini-implante

meiras ativações. Não ocorre osseointegração, portanto a remoção do MI é facilmente obtida. A quantidade de força que pode ser utilizada depende da espessura do MI, da cortical óssea, da distâncias da extremidade externa do MI à cortical óssea. Devido a essas variáveis, é difícil estabelecer um limite de força preciso que pode ser utilizado sobre o MI. Como regra geral, recomenda-se utilizar forças até 400 ou 450gr. Os dispositivos intrabucais convencionais de ancoragem não são capazes de oferecer total eficiência, resultando em movimentações dentárias indesejadas, que podem comprometer o resultado final ou aumentar o tempo total de tratamento. Com a utilização dos microparafusos como unidade de ancoragem, as distalizações são executadas eficientemente, sem efeitos colaterais indesejados ${ }^{23}$.

Blaya et al. ${ }^{24}$ (2010) avaliaram a percepção dos pacientes na mecânica de distalização de molar utilizando-se mini-implantes. A amostra foi composta de 30 pacientes adultos, com má oclusão de Classe II de Angle, nos quais foram instalados mini-implantes no arco superior para se conseguir a distalização do molar. Os pacientes receberam um questionário e responderam a algumas perguntas sobre o tratamento. Os autores concluíram que os mini-implantes foram bem aceitos pelos pacientes e foram eficientes para a distalização dos molares na correção da Classe II.

Acharya et al. ${ }^{25}$ (2012) publicaram um artigo relatando um caso clínico, no qual foi utilizado um mini-implante na região palatina para distalização do molar superior. Após um período de 3 meses da colocação do mini-implante, o tratamento ortodôntico foi iniciado. Os resultados mostraram que os molares foram distalizados com o movimento de corpo em 5 meses, e não houve perda da ancoragem. No final do tratamento, a relação de Classe I de molar e canino foi alcançada. Como conclusão do trabalho, os autores afirmaram que o mini-implante palatino pode ser usado de forma eficaz para a manutenção da ancoragem.

\section{I SCUSSÃ0}

A má oclusão de Classe II apresenta características morfológicas bastante variadas que podem ser causadas tanto por alterações dentárias como por alterações esqueléticas. Quando se trata de um caso de Classe II dentário, há a possibilidade de se fazer um tratamento por meio de distalização de molares superiores, levando-os a uma relação de normalidade com os dentes inferiores. A partir dessa possibilidade é que inúmeros estudos foram realizados na busca de meios alternativos extra e intrabucais, no intento de corrigir a relação molar de Classe II. Dentre os dispositivos extrabucais encontra-se o Aparelho Extra Bucal (AEB). Com relação ao efeito obtido de restrição do crescimento anterior da maxila, promovida pelo $\mathrm{AEB}$, há um consenso entre alguns autores de que esse fato realmente é observado ${ }^{3,5,6,9}$. Os aparelhos Pêndulo e Pendex são considerados distalizadores intrabucais eficientes ${ }^{2,26,27 .}$ Os elásticos intermaxilares também são recursos que podem ser utilizados para a correção da Classe II ${ }^{16,17,20}$.

Aparelhos como o extrabucal e as mecânicas com elásticos de Classe II estão indicados para a distalização dos molares e redução do overjet; no entanto, há necessidade da colaboração do paciente, o que limita a sua eficiência ${ }^{11}$.

Os aparelhos distalizadores de colaboração mínima, ou intrabucais, são mecanismos muito utilizados pelos ortodontistas, pois permitem maior controle mecânico e previsibilidade do resultado ${ }^{28}$. E como recurso mais recente, os mini-implantes também vieram para acrescentar a mecânica de distalização intrabucal ${ }^{23-25}$.

Atualmente, existem diversos tipos e modelos de dispositivos que efetuam a
LOPES MAP

SANTOS DCL

NEGRETE D

FLAIBAN E

O USO DE

DISTALIZADORES

PARA A

CORREÇÃO DA

Má oCLUSÃO DE

CLASSE II

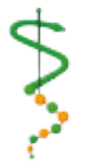

REV. ODONTOL.

UNIV. CID, SÃO

PAULO

2013; 25(3):

$223-32$, SET-DEZ 
LOPES MAP

SANTOS DCL

NEGRETE D :

FLAIBAN E

O USO DE DISTALIZADORES PARA A CORREÇÃO DA MÁ OCLUSÃO DE CLASSE II distalização dos molares. A maioria desses aparelhos utiliza como sistema de ancoragem o botão de Nance associado ao apoio dentário. A ancoragem oferecida por esse sistema não é capaz de evitar totalmente as forças de reação, resultando num componente de força que produz movimento para mesial dos pré-molares e caninos, e para vestibular dos incisivos. Esse efeito colateral indesejado pode acarretar num aumento do tempo de tratamento, pois essas unidades terão que ser movimentadas novamente no sentido contrário, para distal ${ }^{23}$.

De acordo com as pesquisas realizadas na literatura revisada, os aparelhos distalizadores de molares superiores possuem as vantagens e desvantagens descritas na Tabela 1.

TABELA 1

\begin{tabular}{lll}
\hline \hline Vantagens & Desvantagens \\
\hline AEB & $\begin{array}{l}\text { 1. Ação ortodôntica: distalização de } \\
\text { molares (movimento de corpo). }\end{array}$ & $\begin{array}{l}\text { 1. Necessita da cooperação } \\
\text { do paciente. }\end{array}$ \\
$\begin{array}{ll}\text { 2. Pode ter uso ortopédico também. } \\
\text { 3. Pode ter seu uso combinado com } \\
\text { outras técnicas. }\end{array}$ & $\begin{array}{l}\text { 2. Incômodo e esteticamente } \\
\text { desfavorável. }\end{array}$ \\
& $\begin{array}{l}\text { 3. Pode causar inclinação, } \\
\text { intrusão ou extrusão no } \\
\text { molar. }\end{array}$
\end{tabular}

PÊNDULO/PENDEX 1. Conforto.

\section{ELÁSTICO CL II}
1. Mecânica simples
2. Baixo custo
3. Fácil confecção
4. Rápida instalação

MINI-IMPLANTE

REV. ODONTOL.

UNIV, CID , SÃO

2013; 25(3): 223-32, SET-DEZ
2. Uso contínuo.

3. Não há limitações ao comer e falar.

4. Tempo de tratamento.

1. Torque ou rotações no molar, se não for corretamente ativado.

1. Necessita da coloboração do paciente.

2. Movimentos indesejados de extrusão, giro

3. Reabsorção radicular.

1. Instalação relativamente simples.

2. Fácil remoção.

3. Boa aceitação por parte do paciente.

4. Permite aplicação em diversos sítios, possibilitando inúmeras aplicações clínicas.

5. Permite melhorias mais significativas na estética facial, redução do tempo de tratamento, mais discreto e seguro para o paciente quando comparado aos apareIhos extrabucais.

6. Mínima dependência da colaboração do paciente.
1. Risco de perfuração da raiz do dente.

2. Risco de insucesso na estabilidade do MI (10\%).

3. Alto custo 


\section{CONCLUSÃO}

Com base na literatura revisada, no que se refere à possibilidade de distalização de molares superiores, pode-se concluir que os aparelhos distalizadores como: ApareIho Extrabucal (AEB), Aparelho Pêndulo/ Pendex, Elásticos de Classe II e Mini-implantes, são muito utilizados na atuali- dade por sua eficiência em corrigir a Má oclusão de Classe II e possuem vantagens e desvantagens, cabendo ao profissional conhecê-las para eleger, com prudência, a solução terapêutica mais adequada às exigências individuais e profissionais, com o intuito de se obter uma oclusão funcional e esteticamente satisfatória.

\section{REFERÊNCIAS}

1. Manhães FR, Vedovello Filho $M$, Kuramae $M$, Lucato AS, Valdrighi HC. Sistema Ertty para distalização de molares: relato de casos clínicos. Rev Clín Ortodon Dental Press 2009 out/ nov;8(5):76-88.

2. Carano A, Testa M. The distal jet for upper molar distalization. J Clin Orthod 1996 Jul;30(7):374-80.

3. Siqueira D. Estudo comparativo, por meio de análise cefalométrica em norma lateral, dos efeitos dentoesqueléticos e tegumentares produzidos pelo aparelho extrabucal cervical e pelo aparelho de protração mandibular, associados ao aparelho fixo, no tratamento da Classe II, 1a divisão de Angle [Tese]. Bauru: Universidade de São Paulo; 2004.

4. Shimizu RH, Ambrosio AR, Shimizu IA, Godoy-Bezerra J, Ribeiro JS, Staszak KR. Princípios biomecânicos do aparelho extrabucal. Revista Dental Press de Ortodontia e Ortopedia Facial 2004 nov-dez;9(6):122-56.

5. Ricketts R, Bench R, Gugino C, Hilgers J, Schulhof R. Técnica bioprogressiva de Ricketts. Buenos Aires: Médica Panamericana; 1983.

6. Melsen B. Effects of cervical anchorage during and after treatment: an implant study. Am J Orthod 1978 May;73(5):526-40.

7. Burke $M$, Jacobson A. Vertical changes in high-angle Class II, division 1 patients treated with cervical or occipital pull headgear. Am J Orthod Dentofacial Orthop 1992 Dec;102(6):5018.
8. Beckwith FR, Ackerman RJ, Jr., Cobb CM, Tira DE. An evaluation of factors affecting duration of orthodontic treatment. Am J Orthod Dentofacial Orthop 1999 Apr;115(4):439-47.

9. Henriques JFC, Freitas MR, Hayasaki SM. Principais indicações e efeitos da ancoragem extrabucal occipital (I.H.G.) no tratamento de jovens com má oclusão de Classe II, $1^{\text {a }}$ divisão de Angle: apresentação de um caso clínico. Rev Dental Press Ortodon Ortop Facial 1999 4(2):33-8.

10. Nahás A. Estudo cefalométrico das alterações dentoesqueléticas da má oclusão de Class II, divisão 1, tratada com o aparelho de Herbst e com o aparelho extrabucal de tração occipital [Tese]. Bauru: Universidade de São Paulo; 2004.

11. Maria FRT, Janson G, Freitas MR, Henriques JFC. Influência da cooperação no planejamento e tempo de tratamento da má oclusão de Classe II. Revista Dental Press de Ortodontia e Ortopedia Facial 2005 mar-abr;10(2):44-53.

12. Henriques R, Henriques J, Almeida R, Freitas M, Janson G. Estudo das alterações decorrentes do uso do aparelho extrabucal de tração occipital na correção da má oclusão de Classe $I I, 1^{a}$ divisão. Dental Press Ortodon Ortop Facial 2007 jul-ago;12(4):72-83.

13. Bussick TJ, McNamara JA, Jr. Dentoalveolar and skeletal changes associated with the pendulum appliance. Am J Orthod Dentofacial Orthop 2000 Mar;117(3):333-43.
LOPES MAP SANTOS DCL NEGRETE D

FLAIBAN E

O USO DE

DISTALIZADORES

PARA A

CORREÇÃO DA

MÁ OCLUSÃO DE CLASSE II

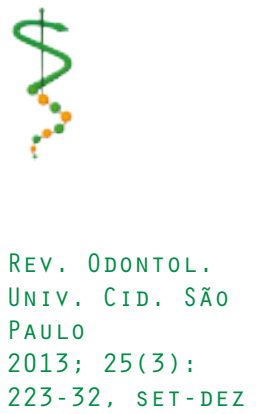


LOPES MAP

SANTOS DCL

NEGRETE D

FLAIBAN E

O USO DE DISTALIZADORES PARA A CORREÇÃO DA MÁ OCLUSÃO DE CLASSE II

\section{2}

I SSN 1983-5183

14. Fuziy A, Rodrigues de Almeida R, Janson G, Angelieri F, Pinzan A. Sagittal, vertical, and transverse changes consequent to maxillary molar distalization with the pendulum appliance. Am J Orthod Dentofacial Orthop 2006 Oct;130(4):502-10.

15. Santos ECA, Silva Filho OG, Reis PMP, Bertoz FA. Distalização dos molares superiores com aparelho Pendex: estudo cefalométrico prospectivo. Revista Dental Press de Ortodontia e Ortopedia Facial 2007 12(4):49-62.

16. Loriato L, Machado A, Pacheco W. Considerações clínica e biomecânicas de elásticos em Ortodontia. RevClin Ortodon Dental Press 2006 5(1):4457.

17. Cabrera MC, Cabrera CAG, Henriques JFC, Freitas MRd, Janson G. Elásticos em Ortodontia: comportamento e aplicação clínica. $R$ Dental Press Ortodon Ortop Facial 2003 jan.-fev.;8(1):115-29.

18. Phillips R. Skinner materiais dentários. 9 ed. Rio de Janeiro: Guanabara Koogan; 1993.

19. Bench R, Gugino C, Hilgers J. Terapia bioprogressiva 3. ed. São Paulo: Santos; 1996.

20. Garbin A, Guedes-Pinto E, Grieco F. Bioprogressiva \& reabilitação neuro-oclusal: a evolução da ortodontia. São Paulo: Somos; 2009.

21. Ferreira Neto J, Caetano MT. A degradação da força de segmentos de elásticos em cadeia de diferentes tamanhos: estudo comparativo in vitro. J Bras Ortodon Ortop Facial 2004 maio-jun;9(51):225-33.
22. Marassi C, Marassi C, Cozer T. Miniimplantes ortodônticos: Ortod. Ortop. Funcional dos Maxilares; 2010. Disponível em: http://www.ortodontista.com/port/artigos/marassi_capitulo_spo_2008.pdf.

23. Villela H, Sampaio A, Lemos L, Limoeiro E. Distalização de molares utilizando microparafusos ortodônticos de titânio autoperfurantes. Rev Clín Ortodon Dental Press 2008 ago-set; 7(4):40-55.

24. Blaya M, Blaya D, Guimarães M, Hirakata L, Marquezan M. Patient's perception on mini-screw used for molar distalization. Rev Odonto Ciênc 2010 25(3):266-70.

25. Acharya S, Prabhakar R, R R. Molar distalisation by palatal implants - a case report. Clinical and Surgical Techiniques 2012 Apr-Jun;4(2):

26. Gianelly A. Distalization of molars with pelling magnets. J Clin Orthod 1988 22(1):40-4.

27. Hilgers JJ. The pendulum appliance for Class II non-compliance therapy. J Clin Orthod 1992 Nov;26(11):706-14.

28. Alves P, Bolognese A, Souza M. Movimento distal de molares usando o Sliding-Jig. Rev Clin Ortodon Dental Press dez. 2005-jan. 2006;4(6):83-9.

Recebido em 18-04-2013

Aceito em 19-08-2013
REV, ODONTOL. UNIV, CID, SÃO 2013; 25(3): 223-32, SET-DEZ: 